\title{
Suplementação de Selênio e Vitamina E sobre a Contagem de Células Somáticas no Leite de Vacas da Raça Holandesa ${ }^{1}$
}

\author{
Juliana Jorge Paschoal ${ }^{2}$, Marcus Antonio Zanetti ${ }^{3}$, José Aparecido Cunha ${ }^{4}$
}

\begin{abstract}
RESUMO - O selênio e a vitamina E são antioxidantes importantes na defesa de células e tecidos e atuam diretamente na manutenção da saúde do úbere, influenciando na contagem de células somáticas, indicador da mastite. O presente trabalho teve como objetivo avaliar o efeito do selênio e da vitamina E sobre a contagem de células somáticas no leite de vacas da raça holandesa. Oitenta e quatro animais foram distribuídos em quatro tratamentos: controle; suplementação com $5 \mathrm{mg} \mathrm{Se/dia;} \mathrm{suplementação} \mathrm{com} 1000$ UI vit. E/dia e suplementação com $5 \mathrm{mg} \mathrm{Se}+1000$ UI vit. E/dia. A suplementação foi iniciada 30 dias antes da provável data de parição, prolongandose até o parto. Amostras do volumoso e do concentrado foram colhidas, quinzenalmente, para análise bromatológica completa e levantamento dos níveis de Se e vit. E. O sangue foi colhido antes do início da suplementação, no parto, 30 e 60 dias após o parto, para determinação dos níveis de Se no soro sangüíneo das vacas. O leite foi colhido semanalmente, para determinação da contagem de células somáticas (CCS). O período de coleta iniciou-se logo após o período colostral, prolongando-se até a décima segunda semana de lactação. Um mês após a suplementação, as vacas que receberam selênio apresentaram níveis séricos superiores ao grupo controle. O selênio diminuiu significativamente a CCS nas oito primeiras semanas de lactação, porém, não foi encontrado efeito da vitamina E e interação entre os dois elementos. A suplementação com selênio no pré-parto aumentou o nível sérico do mineral nas vacas e reduziu a CCS nas oito primeiras semanas de lactação, desempenhando importante papel na resposta imune da glândula mamária de bovinos leiteiros.
\end{abstract}

Palavras-chave: antioxidantes, mastite subclínica, pré-parto, qualidade do leite

\section{Supplementation of Selenium and Vitamin E on Milk Somatic Cell Count of Holstein Cows}

\begin{abstract}
Selenium and vitamin E are important antioxidants for cells and tissues protection acting directly as a support for the udder health. This experiment was designed to evaluate the influence of prepartum selenium and vitamin E supplementation on milk somatic cell counts of Holstein cows. Eighty four animals were allocated into four treatments: control; supplementation with 5 mg Se/ day; supplementation with 1000 UI vitamin E/day and supplementation with $5 \mathrm{mg} \mathrm{Se/day} \mathrm{+} 1000 \mathrm{UI}$ vitamin E/day. The supplementation started thirty days prior to probable parturition date until parturition. Forage and concentrate samples were taken every fifteen days for chemical, selenium and vitamin E analyses. Blood samples were taken before starting supplementation, right after parturition, thirty and sixty days after it to determine the selenium serum levels. Milk samples were taken to determine SCC. Selenium supplemented cows had higher serum selenium concentration compared with control group. The selenium decreased SCC up to $8^{\text {th }}$ week of lactation playing an important role on immune response of bovine mamary gland.
\end{abstract}

Key Words: antioxidants, milk quality, prepartum, subclinical mastitis

\section{Introdução}

Os efeitos favoráveis do selênio (Se), da vitamina (vit.E) e de outros antioxidantes nos mecanismos de defesa da glândula mamária vêm sendo estudados nos últimos anos, porém existem poucos trabalhos desenvolvidos no Brasil. A vit. Eé o mais importante antioxidante lipossolúvel. Está inserida nas membranas lipídicas e as protege contra o ataque de radicais superóxido (Combs \& Combs, 1986). O selênio é um micronutriente essencial presente nos tecidos do corpo. É parte integrante da enzima glutationa peroxidase que atua no citosol celular convertendo peróxido de hidrogênio em compostos atóxicos (Combs \& Combs, 1986).

Um problema de fundamental importância, diz respeito à influência do selênio e da vit. E na incidência de mastite, processo inflamatório que resulta em grandes perdas para a pecuária leiteira. As mastites constituem-se na principal afecção dos animais destinados à produção leiteira; caracterizam-se por alterações físicas, químicas e bacteriológicas do leite, bem como do tecido glandular mamário (Langoni, 2000). 
As mastites são causadas por inúmeros microrganismos, havendo citação na literatura de 137 agentes envolvidos em sua etiologia (Watts, 1998), incluindo-se bactérias, fungos, algas e vírus; entretanto, as mastites de origem bacteriana são as mais freqüentes (Costa et al., 1995; Langoni et al., 1998). No Brasil, a sua incidência é alarmante, acometendo $71 \%$ das vacas em rebanhos de Minas Gerais e São Paulo (Costa et al., 1995a; Costa et al., 1999). A mastite pode ser clínica ou subclínica. A mastite clínica apresenta sintomatologia evidente de processo inflamatório (edema, sensibilidade, hipertermia, hiperemia) e alterações das características da secreção. A mastite subclínica caracteriza-se pela diminuição da produção de leite sem sintomatologia evidente da infecção. Pode ser detectada através do "California Mastitis Test" (Schalm \& Noorlander, 1957), CCS, "Wisconsin Mastitis Test", condutividade elétrica, entre outros (Radostitis et al., 1994).

A CCS é uma ferramenta valiosa na avaliação da incidência de mastite subclínica, na estimativa de perdas de produção de leite e como indicativo da qualidade do leite produzido na fazenda (Fonseca $\&$ Santos, 2000).

A CCS do leite originado de animais sadios é normalmente menor que 300.000 células $/ \mathrm{mL}$ de leite. Entretanto, quando há invasão do úbere por bactérias, ocorre resposta inflamatória que causa grande aumento das células somáticas presentes no leite (Fonseca \& Santos, 2000).

O primeiro estudo feito sobre o efeito do Se e vit. E na incidência de mastite clínica foi reportado por Smith et al. (1984) onde encontraram diminuição de $37 \%$ na incidência de mastite clínica em vacas recebendo suplementação de 740 UI de vit. E por dia, durante o período seco. Injeção de selênio, 21 dias antes do parto, não teve efeito significativo sobre incidência de mastite, no entanto, vacas suplementadas com selênio e vitamina $\mathrm{E}$ tiveram diminuição dos sintomas clínicos de mastite comparadas com aquelas que não receberam nenhum tipo de suplementação.

Resultados bastante satisfatórios foram obtidos quando se estudou o efeito da suplementação de Se ( $0,3 \mathrm{ppm} \mathrm{Se/dia)} \mathrm{e} \mathrm{vit.} \mathrm{E} \mathrm{(1000} \mathrm{UI/dia)} \mathrm{em} \mathrm{novilhas.}$ Iniciou-se a suplementação 60 dias antes do parto, prosseguindo durante toda a lactação. Houve diminuição nos casos de mastite clínica e diminuição na contagem de células somáticas (CCS), quando comparadas com aquelas não suplementadas (Smith et al., 1985).
Alguns trabalhos foram realizados utilizando níveis crescentes de selênio suplementar (Maus et al., 1978). Monitoramento realizado em nove fazendas no Estado de Ohio, durante um ano, avaliou a relação entre altas contagens de células somáticas (CCS) no leite e consumo de selênio e vitamina E. Verificou-se que o consumo de Se variou de 1 a $16 \mathrm{mg} / \mathrm{dia}$ e de vit. E de 100 a 900 mg/dia. A suplementação de Se em níveis crescentes (sendo ideal até $5 \mathrm{mg} / \mathrm{dia}$ ) aumentou a concentração de Se no sangue e diminuiu a incidência de mastite clínica e CCS, significativamente. Do mesmo modo, a suplementação com vit. E em níveis crescentes, aumentou a concentração de alfa tocoferol no sangue (mais significativo em vacas secas) e diminuiu a incidência de mastite clínica (Weiss et al., 1990).

No mesmo ano, Weiss et al. (1990a) analisaram a duração do efeito da suplementação de Se e vit. E no pré e pós-parto, através de experimentos de curta e longa duração. As vacas foram inicialmente divididas em dois grupos: controle e suplementadas com $0,2 \mathrm{ppm}$ de $\mathrm{Se}+70 \mathrm{UI}$ de vit. E/kg de matéria seca (MS), durante o pré-parto. Após a parição, as vacas inicialmente suplementadas, passaram a receber $0,3 \mathrm{ppm}$ de Se e 40 UI vit. E/kg de matéria seca e assim permaneceram até o final do experimento. Vinte e um dias após o parto, 18 vacas do grupo controle, foram distribuídas em três tratamentos recebendo: 0,3 ppm Se/kg de matéria seca; 40 UI vit.E $/ \mathrm{kg}$ de matéria seca e associação dos dois tratamentos, mantendo-se por mais 32 dias. A concentração de Se no plasma do grupo suplementado foi superior ao tratamento controle, não havendo diferença estatística entre o grupo suplementado desde o pré-parto e o grupo suplementado 21 dias pós-parto. Do mesmo modo ocorreu com a concentração de alfa tocoferol no sangue. Com relação à atividade da glutationa peroxidase, o tratamento de longa duração mostrouse superior ao de curta duração e este, por sua vez, superior ao controle.

Weiss et al. (1997) realizaram experimento para avaliar o efeito da administração de vários níveis de vit. E em dietas com baixos níveis de Se. Sessenta e seis animais foram distribuídos em três tratamentos: $100 \mathrm{UI} /$ dia de vit. E durante o período seco + $100 \mathrm{UI} / \mathrm{dia}$ de vit. E durante os primeiros 30 dias de lactação; $1.000 \mathrm{UI} /$ dia de vit. E durante o período seco + $500 \mathrm{UI} /$ dia de vit. E nos primeiros 30 dias de lactação; $1.000 \mathrm{UI} /$ dia de vit. E durante os 46 primeiros dias do período seco + 2.000 UI/ dia de vit. E durante os 14 
últimos dias do período seco +2.000 UI / dia durante o início da lactação. Constatou-se que o tratamento com níveis de 2.000 UI / dia conseguiu manter os níveis de alfa tocoferol adequados no sangue, durante o parto e no período pós-parto, aumentando a taxa de alfa tocoferol nos neutrófilos responsáveis pela saúde do úbere, levando a uma diminuição na incidência de mastite clínica de $25 \%$ para $2,6 \%$, definida por palpação e presença de grumos ou filamentos no leite.

Alguns trabalhos foram feitos no Brasil com objetivo semelhante. Zanetti et al. (1998) concluíram que a suplementação oral com $5 \mathrm{mg}$ de $\mathrm{Se}$, no último mês de gestação, aumentou significativamente o nível sérico do mineral nas vacas leiteiras, reduzindo a incidência de mastite subclínica diagnosticada por intermédio do teste CMT. Os bezerros filhos de vacas suplementadas apresentaram níveis séricos de Se $66 \%$ superiores aos de bezerros filhos de vacas não suplementadas.

O mesmo resultado não foi encontrado por Costa et al. (1997), onde não houve diferença significativa entre o tratamento com Se $(0,1 \mathrm{mg} / \mathrm{kg} \mathrm{MS})$ e o grupo controle (sem suplementação) na incidência de mastite clínica (diagnosticada através da prova de Tamis), mastite subclínica (diagnosticada pelo teste CMT) e infecções intramamárias.

Valle (2000) trabalhou com 77 vacas suplementadas com diferentes níveis de vit. E e constatou maior incidência de mastite clínica no grupo controle comparado aos grupos suplementados, porém, não foi observada diferença entre os grupos com relação à mastite subclínica.

A deficiência de selênio foi constatada em várias regiões do Estado de São Paulo através do levantamento dos níveis de Se nas forragens e nos concentrados (Lucci et al., 1984), assim como no soro sangüíneo de vacas leiteiras (Zanetti et al., 1984).

Existe pouca informação disponível a respeito da concentração de vitamina E em alimentos destinados à alimentação animal, no entanto, sabe-se que a concentração de alfa-tocoferol em forragens decresce rapidamente depois que a planta é cortada; prolongada exposição ao oxigênio e luz solar, aumenta as perdas da atividade da vitamina (Thafvelin \& Oksanen, 1966). Wichtel et al. (1996) analisaram amostras de alimentos conservados e encontraram concentração de $19 \mathrm{mg}$ vit. E/ $\mathrm{kg}$ MS para feno e $34 \mathrm{mg}$ vit. E/ $\mathrm{kg} \mathrm{MS}$, para silagem+pasto verde.

Bovinos leiteiros, no pré-parto, freqüentemente ingerem volumosos conservados de qualidade questionável e o consumo de matéria seca diminui, podendo levar a deficiências em vit. E e selênio.

O objetivo do presente trabalho foi avaliar o efeito da suplementação de selênio e vitamina $E$, realizada no pré-parto, sobre a contagem de células somáticas no leite de vacas da raça holandesa.

\section{Material e Métodos}

O experimento foi conduzido na fazenda Copacabana, município de Descalvado, SP. Trata-se de uma propriedade de grande porte, com produção diária de 23.000 litros de leite, 880 vacas em lactação com média de produção de $26 \mathrm{~kg} / \mathrm{vaca} / \mathrm{dia}$, ordenhadas três vezes ao dia. A ordenha é do tipo carrossel com capacidade para ordenhar até 200 vacas/hora.

Foram utilizadas 84 vacas da raça holandesa, de segunda a quinta lactação, com escores corporais semelhantes. Os animais foram pré-selecionados de acordo com a data prevista de parição, variando de 13/05/2001 a 10/07/2001. Todos os animais selecionados para o experimento foram tratados com antibiótico intramamário específico para vacas secas, no momento da secagem.

As unidades experimentais foram sorteadas em quatro tratamentos, levando-se em consideração a ordem de parição e contagem de células somáticas inicial:

A - $5 \mathrm{mg}$ de selênio na forma de selenito de sódio

B - 1.000 UI de vitamina E na forma de acetato de alfa tocoferol

C $-5 \mathrm{mg} \mathrm{Se}+1.000 \mathrm{UI}$ de vit.E

D - Controle

A suplementação foi efetuada com selenito de sódio (P.A. MERCK), diluído em fubá de milho, de modo que cada $\mathrm{kg}$ do suplemento continha $1.000 \mathrm{mg}$ de selênio. A dose diária foi pesada e colocada em saquinhos de papel $(13,5 \mathrm{~cm} \times 7,0 \mathrm{~cm})$, dobrados adequadamente, para posterior armazenamento em caixas plásticas previamente identificadas.

$\mathrm{O}$ acetato de alfa tocoferol (BASF - Lutavit E $50 \%$ ) também foi diluído em fubá de milho sendo a dose diária colocada em saquinhos de papel $(10,5 \mathrm{~cm} \times 7,0 \mathrm{~cm})$, dobrados adequadamente, para posterior armazenamento em caixas plásticas previamente identificadas.

Os animais foram marcados com quatro diferentes cores relativas a cada um dos quatro tratamentos com objetivo de facilitar o manejo diário. Os saquinhos foram superficialmente passados em melaço e colo- 
cados diretamente na boca dos animais. A suplementação iniciou-se 30 dias antes da provável data de parição de cada animal, prolongando-se até a data do parto.

A alimentação das vacas em lactação consistiu em silagem de milho ( $25 \mathrm{~kg}$ na matéria natural/vaca/ dia), resíduo de cervejaria (6 kg na matéria natural/ vaca/dia), capim verde (5 kg na matéria natural/vaca/ dia) e concentrado formulado e misturado na própria fazenda $(13,7 \mathrm{~kg}$ na matéria natural/vaca/dia). Todos os ingredientes foram pesados em um vagão misturador e fornecidos aos animais, duas vezes ao dia.

As vacas secas receberam silagem de milho $(22 \mathrm{~kg}$ na matéria natural/vaca/dia), silagem de capim napier (5 kg na matéria natural/vaca/dia) e concentrado formulado e misturado na própria fazenda (4 kg na matéria natural/vaca/dia). Todos os ingredientes foram pesados em um vagão misturador e fornecidos aos animais pela manhã.

Amostras de volumoso e concentrado fornecidas às vacas secas foram colhidas quinzenalmente, diretamente do cocho, secas em estufa a $65^{\circ} \mathrm{C}$, moídas e reservadas para posterior análise. Vinte por cento de cada amostra foram selecionados para a formação de um "pool" o qual foi submetido às análises de MS, PB, EE, MM, Ca, P de acordo com AOAC (1990), FDN (Goering \& Van Soest, 1970), selênio (Olson et al., 1975) e vitamina E (Bianchini \& Penteado, 1999).

Foram realizadas quatro colheitas de sangue, em cada vaca, para análise do selênio (antes da suplementação, no dia do parto, 30 e 60 dias após o parto). As amostras de sangue, para análise do selênio, foram colhidas da veia mamária em tubos com vácuo, transportadas ao laboratório e centrifugadas por 4 minutos. $\mathrm{O}$ soro foi pipetado, acondicionado em eppendorfs de plástico e congelado a $-20^{\circ} \mathrm{C}$. As análises laboratoriais para determinação do selênio, foram realizadas após a digestão úmida com ácido perclórico $70 \%$ e posterior leitura fluorimétrica, seguindo-se a sensibilização por diamino-naftaleno (Olson et al., 1975).

As colheitas de leite para levantamento da CCS foram realizadas semanalmente, logo após o período colostral (total de 8 semanas de coleta), durante a ordenha da tarde, seguindo a rotina geral de ordenha, onde, após a pré-imersão e secagem dos tetos com papel toalha, $20 \%$ do leite total ordenhado foram automaticamente colhidos, através do uso de tubo coletor próprio acoplado à máquina, permitindo amostragem do início, meio e final da ordenha. Após esgotamento do leite, foi executada a pós-imersão dos tetos em solução de iodo $(0,5 \%)$. Os tubos plásticos, com capacidade de $60 \mathrm{~mL}$, contendo 1 a 2 pastilhas do conservante dicromato de potássio, foram utilizados para colheita de leite. As amostras foram previamente identificadas, acondicionadas em caixas especiais para transporte e levadas o mais rapidamente ao laboratório. A CCS foi realizada eletronicamente (BENTLEY $\left.{ }^{\circledR} 300\right)$.

Odelineamento utilizado foi em blocos casualizados (DBC), onde os blocos foram elaborados de acordo com a ordem de parição dos animais.

Os níveis de selênio no soro foram comparados em cada tempo de colheita utilizando PROC GLM do SAS (1982).

Por não seguirem uma distribuição normal, os valores de contagem de células somáticas (CCS) foram transformados em loge e, desta forma, reportados. Os dados foram analisados usando PROC MIXED do SAS (1982).

\section{Resultados e Discussão}

O teor médio do selênio na dieta basal durante o período experimental foi de $0,52 \mathrm{mg} / \mathrm{kg} \mathrm{MS}(0,52 \mathrm{ppm})$, valor superior ao que foi encontrado nas fazendas do Estado de São Paulo na década de oitenta (Lucci et al., 1984) e no Estado de Ohio, EUA (Weiss et al., 1990). Atualmente, estão sendo utilizados níveis superiores de selênio, sendo o sal mineral a principal via de fornecimento. Os animais deste experimento, suplementados com $5 \mathrm{mg}$ de selênio/dia, passaram a consumir 10,62 mg de selênio diário ou 0,98 ppm, valores similares aos testados por Maus et al. (1980) e Weiss et al. (1990).

A concentração de vitamina E encontrada na dieta basal foi $22,6 \pm 0,97 \mathrm{UI} / \mathrm{kg}$ MS (22,6 mg/kg MS). Wichtel et al. (1996), encontraram concentração de $19 \mathrm{mg}$ vit. E/kg MS para feno e $34 \mathrm{mg}$ vit. E/kg MS, para silagem+pasto verde, valores bastante próximos do valor encontrado neste trabalho. Os animais suplementados com 1000 UI de vitamina E/dia, passaram a consumir 1244 UI por dia, valores similares aos utilizados por Smith et al. (1985) e Weiss et al. (1990a).

Os níveis séricos do selênio no período precedente à suplementação, no parto, 30 e 60 dias após o parto estão apresentados na tabela a seguir:

Pelos resultados, observou-se que antes do início dos tratamentos, os níveis séricos do selênio foram semelhantes $(0,051 ; 0,049$ e $0,051 \mathrm{mg} / \mathrm{mL}$ para os 
Tabela 1 - Níveis séricos do selênio

Table 1 - Selenium serum levels

\begin{tabular}{lcccc}
\hline $\begin{array}{l}\text { Períodos } \\
\text { Periods }\end{array}$ & \multicolumn{3}{c}{$\begin{array}{c}\text { Tratamentos } \\
\text { Treatments }\end{array}$} \\
\cline { 2 - 5 } & $\mathrm{AP}^{1}(\mathrm{mg} / \mathrm{mL})$ & $\mathrm{P}(\mathrm{mg} / \mathrm{mL})$ & $30 \mathrm{PP}(\mathrm{mg} / \mathrm{mL})$ & $60 \mathrm{PP}(\mathrm{mg} / \mathrm{mL})$ \\
\hline $\begin{array}{l}\text { Controle } \\
\text { Se }\end{array}$ & $0,051^{\mathrm{a}}$ & $0,071^{\mathrm{b}}$ & $0,093^{\mathrm{a}}$ & $0,089^{\mathrm{a}}$ \\
$\begin{array}{l}\text { Selenium } \\
\text { Se + vit. E }\end{array}$ & $0,048^{\mathrm{a}}$ & $0,081^{\mathrm{a}}$ & $0,095^{\mathrm{a}}$ & $0,091^{\mathrm{a}}$ \\
$\begin{array}{l}\text { Selenium +vit.E } \\
\text { E.P.M. }\end{array}$ & $0,051^{\mathrm{a}}$ & $0,083^{\mathrm{a}}$ & $0,092^{\mathrm{a}}$ & $0,089^{\mathrm{a}}$ \\
\hline
\end{tabular}

Médias seguidas de letras diferentes na coluna diferem pelo teste de Tukey $(P<0,05)$.

${ }^{1} \mathrm{AP}$ - Antes do parto; P - Parto; 30PP - 30 dias pós-parto; 60PP - 60 dias pós-parto.

2 Erro-padrão da média.

Means in a colum followed by different letters are diferent by Tukey's Test $(P<0,05)$.

${ }_{1}^{1} A P$ - prepartum; $P$ - parturition; $30 P P$ - 30 days after parturition; $60 P P-60$ days after parturition.

2 Standard error of mean.

tratamentos Controle, Selênio e Selênio+vit.E, respectivamente), valores superiores aqueles encontrados por Zanetti et al. (1984), fato explicado pela maior concentração de selênio encontrada na dieta basal. Estes níveis denotam insuficiência do mineral, uma vez que o valor recomendável para o aumento da resistência da glândula mamária é de $0,080 \mathrm{mg} / \mathrm{mL}$ (Weiss et al. 1990). No momento do parto, ou seja, um mês após a suplementação, vacas que receberam selênio ou selênio associado à vitamina $\mathrm{E}$ apresentaram níveis séricos superiores $(\mathrm{P}<0,05)$ ao grupo Controle $(0,081 ; 0,083 ; 0,071 \mathrm{mg} / \mathrm{mL}$, respectivamente), alcançando os níveis recomendados, o que mostrou ser suficiente o período de suplementação utilizado. Esses resultados concordam com os obtidos por Zanetti et al. (1998), os quais encontraram aumento significativo nos níveis séricos de selênio, após 30 dias de suplementação com o mineral. Conquanto, os níveis alcançados situaram-se ao redor de $0,068 \mathrm{mg} / \mathrm{mL}$, mais baixos que os encontrados neste experimento, provavelmente devido aos baixos níveis do selênio encontrados na dieta. De acordo com Maus et al. (1980), a suplementação com 6 mg selênio/dia conseguiu manter a concentração sérica do selênio em níveis adequados e semelhantes aos obtidos neste trabalho.

Trinta dias após o parto, os níveis séricos do selênio igualaram-se. Tal fato pode ser explicado pelo término da suplementação e pela alteração da dieta de todos os animais, pois, estando em produção, todos os grupos passaram a receber maior quantidade de concentrado por dia e, conseqüentemente, maior quantidade de selênio.

Segundo Weiss et al. (1990), a concentração do selênio no plasma sanguíneo estava correlacionada com a concentração do selênio na dieta para vacas secas, porém, a mesma correlação não fora encontrada para as vacas em lactação. A discrepância entre estes dados pode estar relacionada ao maior fornecimento de selênio aos animais em produção, onde, após certo nível de suplementação ( $5 \mathrm{mg} / \mathrm{dia})$, a concentração plasmática do selênio atingira um platô de $0,08 \mathrm{mg} / \mathrm{mL}$.

Por não seguirem uma distribuição normal, os resultados relativos à contagem de células somáticas (CCS) nas oito primeiras semanas de lactação, foram transformados em loge e estão apresentados na Tabela 2.

Analisando esses resultados, na presença e na ausência de selênio (Tabela 3), observou-se que o selênio diminuiu significativamente $(\mathrm{P}<0,05)$ a CCS nas primeiras oito semanas de lactação (Figura1), com efeito de interação entre semana $\mathrm{x}$ tratamento nas semanas 4 e $6(\mathrm{P}<0,05)$. Levando em consideração o período total de doze semanas, o selênio não apresentou efeito significativo $(\mathrm{P}=0,14)$, possivelmente explicado pela "diluição" do efeito à medida que se afasta do período de suplementação.

Não houve efeito da vitamina $E$ durante as oito primeiras semanas de lactação (Tabela 3 e Figura 2) e nem durante o período total de doze semanas.

Não foi encontrada interação significativa entre os dois elementos, provavelmente, explicado pelo fato dos requerimentos de selênio e vitamina E serem dependentes das suas concentrações no organismo. De acordo com Combs \& Combs (1986), a vitamina E, atuando sobre a manutenção da integridade das membranas, reduz as exigências de selênio e, portanto, a quantidade de glutationa peroxidase necessária 
para destruição de peróxidos formados no citosol celular, mantendo, dessa forma, a capacidade celular de destruir os patógenos. O selênio, por sua vez, poupa a vitamina $E$ através da enzima glutationa peroxidase, reduzindo a quantidade requerida da mesma para a manutenção da integridade das membranas lipídicas. Os resultados desta pesquisa concordam com os obtidos por Weiss et al. (1990), os quais encontraram alta correlação entre a CCS e a concentração do selênio no sangue, porém não verificaram correlação entre níveis de vitamina $E$ no sangue e a CCS $(\mathrm{P}<0,25)$. Do mesmo modo, Zanetti et al. (1998) encontraram diminuição de mastite subclínica diagnosticada por intermédio do teste CMT $(\mathrm{P}<0,10)$ em vacas recebendo selênio, porém não encontraram efeito da vitamina E. Costa et al. (1997) não obtiveram resultados positivos com a suplementação de selênio, provavelmente explicado

Tabela 2 - Resultados relativos à CCS $\left(\log _{e}\right)$ até a oitava semana de lactação, de acordo com os tratamentos Table 2 - SCC data $\left(\log _{e}\right)$ up to $8^{\text {th }}$ lactation week, according to the treatments

\begin{tabular}{|c|c|c|c|c|c|c|c|c|c|}
\hline & \multicolumn{8}{|c|}{$\begin{array}{c}\text { Semana } \\
\text { Week }\end{array}$} & \multirow[b]{2}{*}{$\begin{array}{c}\text { Média } \\
\text { Mean }\end{array}$} \\
\hline & 1 & 2 & 3 & 4 & 5 & 6 & 7 & 8 & \\
\hline $\begin{array}{l}\text { Controle } \\
\text { Control }\end{array}$ & 6,21 & 5,64 & 6,30 & 6,41 & 5,43 & 5,45 & 5,22 & 5,15 & 5,73 \\
\hline $\begin{array}{l}\text { Se } \\
\text { Selenium }\end{array}$ & 5,41 & 6,15 & 6,31 & 6,31 & 5,58 & 5,19 & 4,62 & 4,84 & 5,55 \\
\hline $\begin{array}{l}\text { vit.E } \\
\text { Vitamin E }\end{array}$ & 6,23 & 5,83 & 5,75 & 6,35 & 5,93 & 6,53 & 5,81 & 5,98 & 6,05 \\
\hline $\begin{array}{l}\text { Se+vit.E } \\
S e+v i t . E\end{array}$ & 5,60 & 5,19 & 4,11 & 4,06 & 4,56 & 4,28 & 4,85 & 5,44 & 4,76 \\
\hline E.P.M. ${ }^{1}$ & 0,65 & 0,69 & 0,55 & 0,65 & 0,65 & 0,54 & 0,47 & 0,54 & 0,39 \\
\hline
\end{tabular}

${ }^{1}$ Erro-padrão da média (Standard error of mean).

Tabela 3 - Resultados relativos à CCS $\left(\log _{e}\right)$ até oitava semana de lactação, na presença de selênio e vitamina $E$ Table 3 - SCC data $\left(\log _{e}\right)$ up to $8^{\text {th }}$ lactation week on presence of selenium and vitamin E

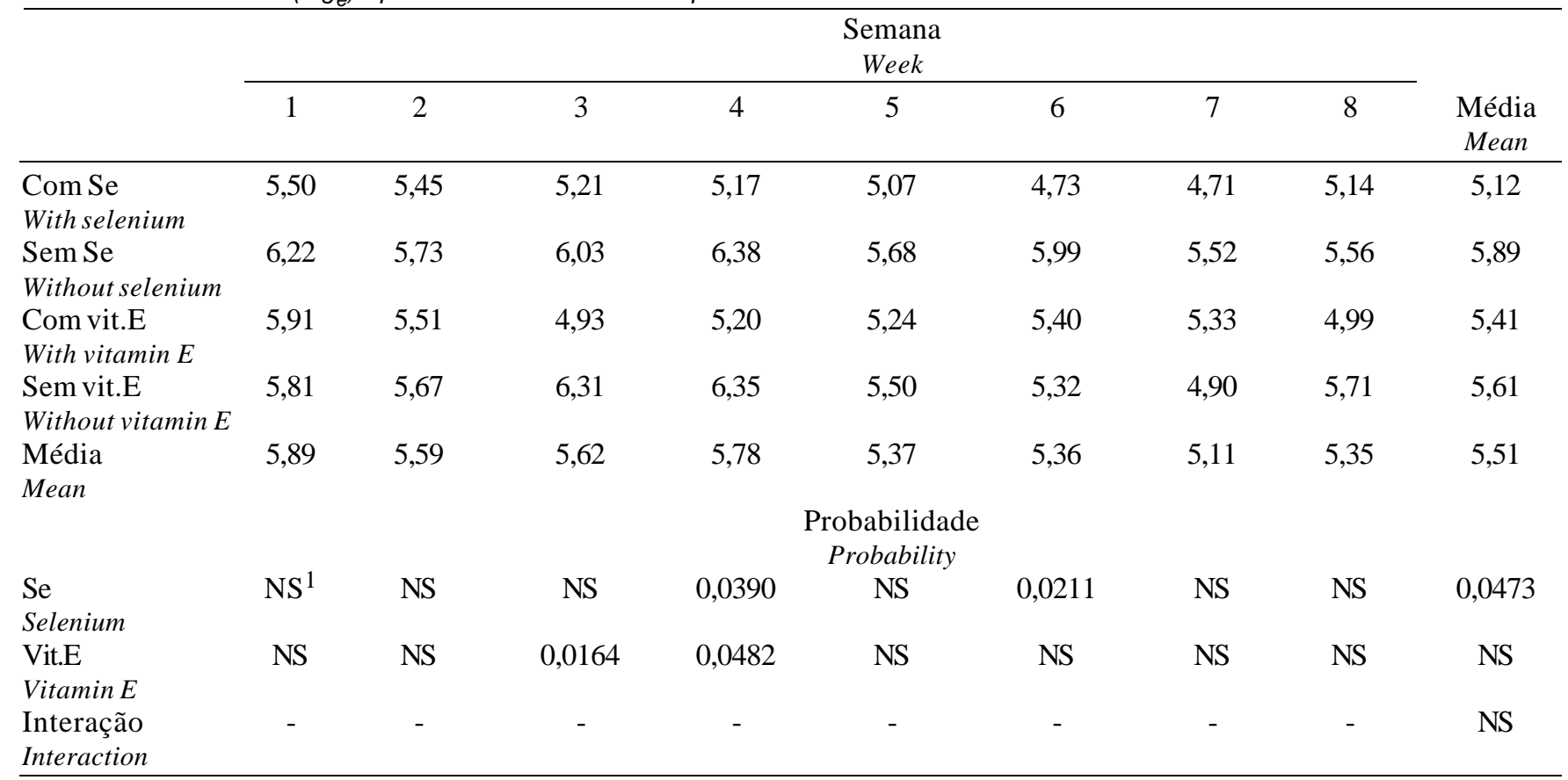

${ }^{1}$ Não significativo $(P>0,05)$ (Not significant).

R. Bras. Zootec., v.32, n.6, p.2032-2039, 2003 (Supl. 2) 


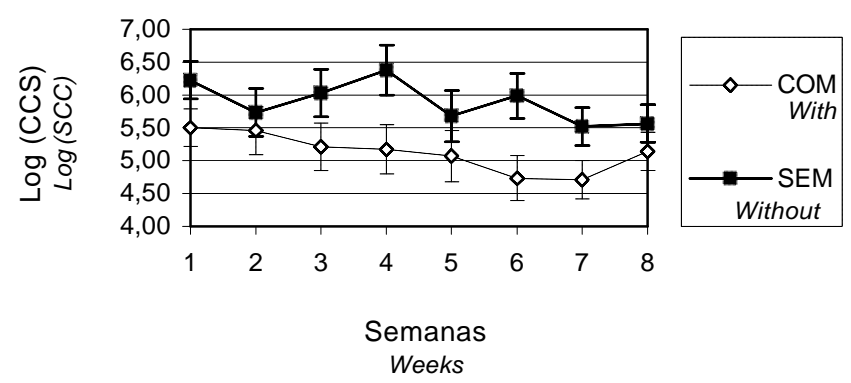

Figura 1 - CCS, $\log _{e}$ até oitava semana de lactação, na presença do selênio.

Figure 1 - SCC $\left(\log _{e}\right)$ up to $8^{\text {th }}$ week of lactation on presence of selenium.

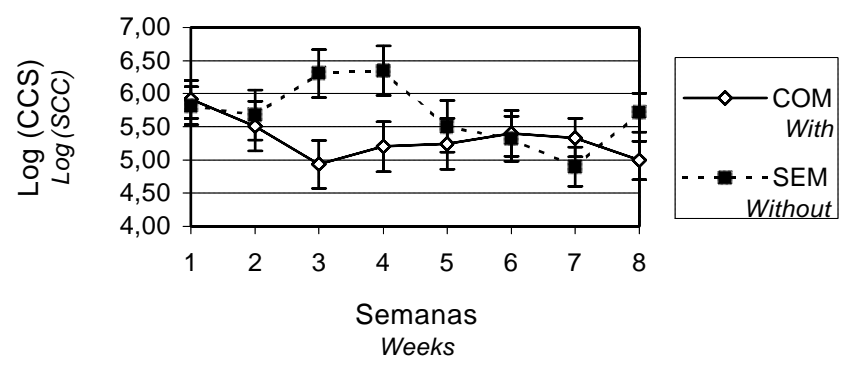

Figura 2 - CCS, $\log _{e}$ até oitava semana de lactação, na presença da vitamina $\mathrm{E}$.

Figure 2 - $S C C, \log _{e}$ up to $8^{\text {th }}$ week of lactation on presence of vitamin $E$.

pelo baixo nível utilizado. Valle (2000) não encontrou efeito da vitamina $\mathrm{E}$ sobre a incidência de mastite subclínica, concordando com os resultados do presente trabalho. Weiss et al. (1997) encontraram resultado benéfico da vitamina $\mathrm{E}$ sobre a incidência de mastite, quando utilizaram níveis mais altos de suplementação.

A CCS, durante as oito primeiras semanas de lactação, foi afetada pela suplementação com selênio, por ter prevenido a supressão da função dos neutrófilos durante o início do período de lactação.

\section{Conclusões}

A suplementação com selênio, realizada 30 dias antes do parto, trouxe efeitos benéficos à saúde da glândula mamária pela diminuição na contagem de células somáticas do leite, diagnosticada até oitava semana de lactação. Pode ser usada como ferramenta auxiliar na maximização da resposta imune do animal, não substituindo a implantação das medidas tradicionais de controle da mastite.

\section{Literatura Citada}

ASSOCIATION OF OFFICIAL ANALYTICAL CHEMISTS - AOAC. Official methods of analysis. 12.ed. Washington, D.C.: 1975. 1094p.

BIANCHINI, R.; PENTEADO, M.V.C. Teores de retinol, betacaroteno e alfa-tocoferol em leites bovinos comercializados na cidade de São Paulo. Ciência e Tecnologia de Alimentos, v.19, p.349-355, 1999.

COMBS Jr., G.F.; COMBS, S.B. The role of selenium in nutrition. London: Academic Press, 1986. 180p.

COSTA, E.O.; BENITES, N.R.; MELVILLE, P.A. et al. Estudo etiológico da mastite clínica bovina. Revista Brasileira de Medicina Veterinária, v.17, p.156-158, 1995.

COSTA, E.O.; LUCCI, C.S.; ABE, S.Y. et al. Influência da suplementação de selênio na incidência de mastite. Revista Brasileira de Medicina Veterinária, v.19, p.169-172, 1997.

COSTA, E.O.; MELVILLE; P.A.; RIBEIRO, A.R. et al. Índices de mastite bovina clínica e subclínica nos Estados de São Paulo e Minas Gerais. Revista Brasileira de Medicina Veterinária, v.17, p.215-217, 1995a.

COSTA, E.O.; RIBEIRO, A.R.; WATANABE, E.T. et al. Mastite subclínica: prejuízos causados e os custos de prevenção em propriedades leiteiras. Revista Napgama, v.2, p.16-20, 1999.

FONSECA, L.F.L; SANTOS, M.V. Qualidade do leite e controle de mastite. 1.ed. São Paulo: Lemos Editorial, 2000. 175 p.

GOERING, G.K.; Van SOEST, P.J. Forage fiber analysis (apparatus, reagents, procedures and some applications). USDA Agriculture Handbook, n. 379, Washington D.C., 1970.

LANGONI, H. Tendências de modernização do setor lácteo: monitoramento da qualidade do leite pela contagem de células somáticas. Revista educação Continuada CRMV-SP, v.3, p.57-64, 2000.

LANGONI, H.; DOMINGUES, P.F.; SILVA, A.V. et al. Aspectos etiológicos na mastite bovina. Revista Brasileira de Medicina Veterinária, v.20, p.204-210, 1998.

LUCCI, C.S.; MOXON, A.L.; ZANETTI, M.A. et al. Selênio em bovinos leiteiros do estado de São Paulo. I. Níveis de Selênio em soros sangüíneos. Revista Faculdade de Medicina Veterinária e Zootecnia da Universidade de São Paulo, v.21, p.65-70, 1984.

MAUS, R.F.; MARTZ, F.A; BELYEA, .L. et al. Relationship of diet selenium to selenium in plasma and milk from dairy cows. Journal of Dairy Science, v.63, p.533-537, 1980.

OLSON, O.E.; PALMER, L.S.; CARY, E.L. Modification of the official Fluorimetric method for selenium in plants. Journal of Association of Official Analytical Chemists, v.58, p.117-121, 1975.

RADOSTITS, O.M.; BLOOD, D.C.; GAY, C.C. Veterinary Medicine. London: Bailliere-Tindall, 1994. 173p.

STATISTICAL ANALYSIS SYSTEM - SAS. SAS user's guide: statistics version. 5ed. Cary, NC : SAS Institute Inc, 1982.

SCHALM, O.W.; NOORLANDER, D.O. Experimental evidence and observation leading to development of California Mastitis Test. Journal of American Veterinary Medicine Association, v.138, p.199-204, 1957.

SMITH, K.L.; HARRISON, J.H.; HANCOCK, D.H. et al. Effect of vitamin $E$ and selenium supplementation on incidence of clinical mastitis and duration of clinical symptoms. Journal of Dairy Science, v.67, p.1293-1300, 1984.

SMITH, K.L.; CONRAD, H.R.; AMIET, B.A. et al. Incidence of environmental mastitis as influence by vitamin $\mathrm{E}$ and 
selenium. Kielie Milchwirtsch Forschungsber, v.37, p.482, 1985.

THAFVELIN, B.; OKSANEN, H.E. Vitamin E and linolenic acid content of hays as related to different drying conditions. Journal of Dairy Science, v.49, p.282-286, 1996.

VALLE, C.R. Influência da suplementação de vitamina E nos períodos pré e pós-parto na ocorrência de mastite clínica. Pirassununga: Universidade de São Paulo, 2000. 76p. Dissertação (Mestrado em Zootecnia) - Universidade de São Paulo, 2000.

WATTS, J.L. Etiological agents of bovine mastitis. Veterinary Microbiology, v.16, p.41-46, 1998.

WEISS, W.P.; HOGAN, J.S.; SMITH, K.L.et al. Relationship among selenium, vitamin $\mathrm{E}$ and mammary gland health in commercial dairy herds. Journal of Dairy Science, v.73, p.381-390, 1990.

WEISS, W.P.; HOGAN, J.S.; TODHUNTER, D.A. et al. Effect of vitamin E supplementation in diets with a low concentration of Selenium on mammary gland health of dairy cows. Journal of Dairy Science, v.80, p.1728-1737, 1997.

WEISS, W.P.; TODHUNTER, D.A.; HOGAN, J.S. et al. Effect of duration of supplementation of Selenium and Vitamin E on periparturient dairy cows. Journal of Dairy Science, v.73, p.3187-3194, 1990a.
WICHTEL, J.J.; FREEMAN, D.A.; CRAIGIE, A.L. et al. Alphatocopherol, selenium and polyunsaturated fatty acid concentration in the serum and feed of spring-calving dairy heifers. New Zealand Veterinary Journal, v.44, p.15-21, 1996.

ZANETTI, M.A.; LUCCI, C.S.; MEIRELLES, G.J.R. Selênio em bovinos leiteiros do Estado de São Paulo. V. Suplementação de Selênio para vacas em fase final de gestação. Revista da Faculdade de Medicina Veterinária e Zootecnia da Universidade de São Paulo, v.21, p.141-145, 1984.

ZANETTI, M.A.; NEUNHAUS, L.E.D.; SCHALCH, E.D. et al. Efeito da suplementação de Selênio e Vitamina Eem bovinos leiteiros. Revista Brasileira de Zootecnia, v.27, p.405408, 1998.

Recebido em: 14/10/02

Aceito em: 10/04/03 